\title{
Analisis Pemanfaatan Limbah Padat Pabrik Kelapa Sawit menjadi Bahan Bakar PLTU (Studi Kasus : PT. Agro Mitra Madani Kabupaten Tanjung Jabung Barat)
}

\author{
G.M.Saragih ${ }^{1}$, Hadrah $^{2 *}$, Rahmad Fatulloh ${ }^{3}$ \\ 1,2,3 Prorgam Studi Teknik Lingkungan, Fakultas Teknik, Universitas Batanghari \\ Jl. Slamet Riyadi, Broni, Kota Jambi \\ *correspondence email: hadrah@unbari.ac.id
}

\begin{abstract}
Palm oil mills as raw materials for domestic industry and are the main export commodities can potentially produce solid waste that needs to be treated in order to avoid environmental pollution. The best treatment is if the waste is used as an energy source. The study was conducted to determine the energy produced from the utilization of palm shell and palm fiber solid waste carried out at PT Agro Mitra Madani, Tanjung Jabung Barat District, Jambi Province. This study aims to determine the number of shells and fibers produced and used as materials for boilers, analysis of electrical energy from solid waste of palm shells and fibers, and mass balance analysis from the burning of shells and fibers. The composition of the boiler is $25 \%$ shell and $75 \%$ fiber. The energy used by factories from shell and fiber solid waste is the amount of energy produced multiplied by the length of shift time, which is 7 hours. The plant's electricity demand is 4,900 kWh and the amount of electricity produced from the fibers and shells as boiler fuel is $8,253 \mathrm{kWh}$. Based on the calculation results, it can be seen that the excess power for 7 hours is $3,353 \mathrm{kWh}$ and the amount of residue is $654 \mathrm{~kg} /$ shift. These results indicate that the utilization of oil palm shells and fiber into electrical energy is feasible.
\end{abstract}

Keywords: Renewable Energy, Electrical Energy, Fibers and Shells.

\section{Pendahuluan}

Kelapa sawit (Elaeis guineensis jacq) adalah tumbuhan industri penghasil minyak goreng, minyak industri, maupun bahan bakar biodiesel. Pada tahun 2017, perkebunan kelapa sawit di Indonesia dengan luas areal 12,29 juta ha, produksi 34,46 juta ton dan ekspor 29,071 juta ton CPO. Kelapa sawit mempunyai peranan penting dalam perekonomian nasional. Disamping sebagai bahan baku industri dalam negeri, kelapa sawit juga merupakan komoditas ekspor utama. Pada tahun 2017 tercatat di Provinsi Jambi perkebunan kelapa sawit mencapai 1.701.363 ha di 9 kabupaten (BPS Indonesia 2017).

Pemanfaatan limbah padat dari Pabrik Kelapa Sawit (PKS) dapat dilakukan dengan menggunakannya sebagai bahan baku boiler pada pembangkit listrik tenaga uap. Boiler atau ketel uap adalah suatu bejana/wadah yang di dalamnya berisi air atau fluida lain untuk dipanaskan. Energi panas dari fluida tersebut selanjutnya digunakan untuk berbagai macam keperluan, seperti untuk turbin uap, pemanas ruangan, mesin uap, dan lain sebagainya. Secara proses konversi energi, ketel memiliki fungsi untuk mengkonversi energi kimia yang tersimpan di dalam bahan bakar menjadi energi panas yang tertransfer ke fluida. Dapat diketahui bahwa syarat bahan bakar ketel harus memiliki nilai kalor yang cukup untuk mengubah air menjadi uap, serta nilai kalor suatu bahan bakar juga sangat berpengaruh terhadap efisiensi boiler itu sendiri (Kunarto, 2019).

Berdasarkan hasil penelitian oleh Suci Angraini Pricilia (2014) disimpulkan bahwa bahan bakar cangkang penggunaanya habis 5 ton/jam dengan lama penggunaan 4,1 jam dan serabut 6,5 ton/jam dengan lama penggunaan 6,8 jam setiap hari. Berdasarkan hasil perkalian antara lama penggunaan bahan bakar dengan kebutuhan listrik pabrik sebesar $815 \mathrm{~kW}$, maka diperoleh energi dari cangkang sebesar $3.416 \mathrm{kWh}$ dan serabut sebesar $5.617 \mathrm{kWh}$ dengan total energi pemanfaatan serabut dan cangkang sebesar $9.033 \mathrm{kWh} / \mathrm{hari}$.
Upaya untuk menjaga kelestarian lingkungan telah dilakukan oleh beberapa perusahaan dengan mengelola limbah cair menjadi pupuk dan limbah padat sebagai bahan bakar boiler pengganti solar yang ramah lingkungan, seperti halnya yang dilakukan oleh PT AMM, Kabupaten Tanjung Jabung Barat, Provinsi Jambi. PT AMM telah memanfaatkan serabut dan cangkang kelapa sawit sebagai bahan bakar boiler yang menghasilkan uap (steam) untuk menggerakkan turbin yang akan menghasilkan energi listrik. Listrik digunakan untuk menggerakkan mesin-mesin yang terdapat di pabrik, barak (perumahan karyawan pabtrik), kantor, dan penerangan untuk lingkung pabrik.

\section{Metode Penelitian}

\section{a. Pengumpulan Data Primer}

1. Jumlah produksi olah TBS Jumlah olah TBS x jam olah

2. Volume limbah padat PKS Jumlah cangkang = jumlah olah TBS x $6 \%$ Jumlah serabut $=$ jumlah olah TBS $\times 13 \%$

3. Jumlah residu pembakaran pada boiler.

b. Pengumpulan Data Sekunder

1. Kapasitas boiler PT AMM

Data yang diambil meliputi spesifikasi boiler yang dipakai pada PT AMM, steam pressure superheater (bar), temperatur feed tank dearator $\left({ }^{0} \mathrm{c}\right)$, steam flow (ton/jam) dan steam out generatour $\left({ }^{0} \mathrm{c}\right)$.

2. Layout PKS PT AMM

Data yang di ambil bertujuan untuk mengetahui susunan tata letak kantor, gudang, IPAL, dan stasiunstasiun yang terdapat di PKS PT AMM.

3. Peta PKS PT AMM 
Untuk membantu peneliti sebelum melakukan survei untuk mengetahui kondisi daerah yang akan diteliti di PT AMM.

\section{c. Neraca Massa dari Proses Pembakaran pada Boiler}

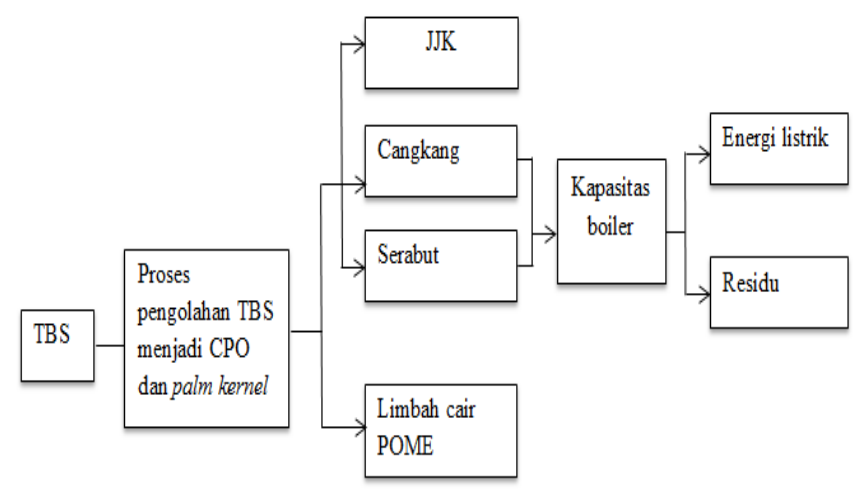

Gambar 1. Neraca limbah PKS

\section{Hasil dan Pembahasan}

\section{a. Neraca Massa Limbah PKS PT Agro Mitra Madani}

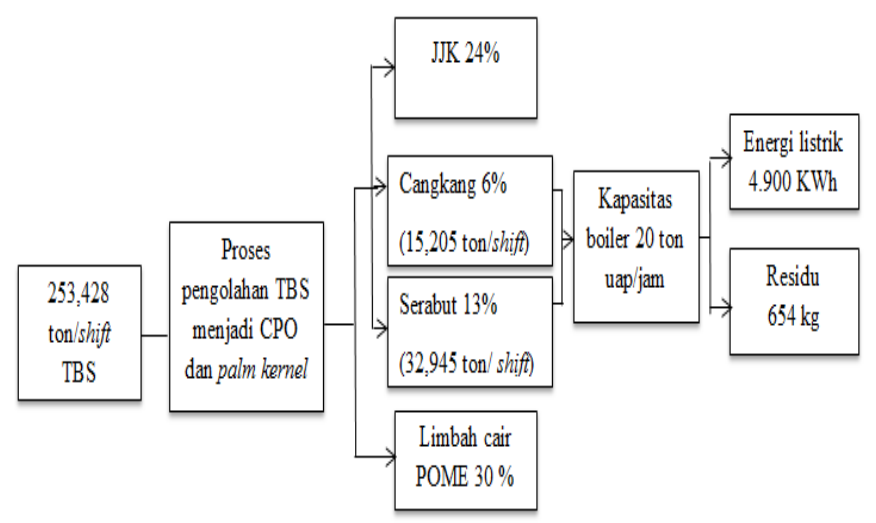

Gambar 2. Neraca massa limbah PKS PT AMM

Tandan Buah Segar yang diolah di pabrik menghasilkan CPO, inti sawit, serabut, cangkang, dan tandan kosong. Dalam proses pengolahan sawit, pabrik AMM ini menghasilkan limbah padat dan limbah cair. Limbah padat berupa serabut dan cangkang yang dimanfaatkan sebagai bahan bakar boiler yang akan menghasilkan listrik untuk memenuhi kebutuhan yang diperlukan di PT AMM.

Jumlah olah TBS x 7 jam olah (shift)

$=36,204$ ton $\mathrm{x} 7$ jam olah

$=253,428 \mathrm{ton} / \mathrm{shift}$.

\section{b. Jumlah Persentase Limbah di PT Agro Mitra Madani}

Adapun cara menghitung umlah persentase limbah padat dan limbah cair di PT AMM ialah sebagai berikut:

1. Limbah janjangan kosong

Jumlah Olah TBS/shift x Persentase Janjangan Kosong $=253,428 \mathrm{ton} /$ shift $\mathrm{x} 24 \%$

$=60,822 \mathrm{ton} /$ shift

2. Limbah Cangkang

Jumlah Olah TBS/shift x Persentase Cangkang

$=253,428$ ton $/$ shift $\times 6 \%$

$=15,205$ ton $/$ shift
3. Limbah Serabut

Jumlah Olah TBS/shift x Persentase Serabut

$=253,428 \mathrm{ton} /$ shift $\mathrm{x} 13 \%$

$=32,945 \mathrm{ton} /$ shift

4. Limbah Cair

Jumlah Olah TBS/shift x Persentase Tandan Kosong

$=253,428$ ton $/$ shift $\times 30 \%$

$=76,028 \mathrm{ton} /$ shift

c. Alur Proses Pemanfaatan Limbah Padat Menjadi Listrik Tenaga Uap PT Agro Mitra Madani

PT AMM menggunakan fluida kerja air uap yang bersirkulasi secara tertutup. Siklus tertutup artinya menggunakan fluida yang sama secara berulang-ulang. Urutan sirkulasinya adalah sebagai berikut :

1. Pertama bahan bakar berupa limbah padat cangkang dan serabut dengan komposisi serabut $75 \%$ dan cangkang $25 \%$ dimasukkan kedalam ruang pembakaran dengan cara dimasukkan melalui fuel distributing conveyor.

2. Kedua air diisikan ke ketel uap hingga mengisi penuh seluruh luas permukaan pemindah panas. Di dalam boiler air ini dipanaskan dengan gas panas hasil bakaran bahan bakar dengan udara sehingga berubah menjadi uap dengan suhu di dalam boiler berkisar $250-350^{\circ} \mathrm{C}$.

3. Ketiga, uap hasil produksi boiler dengan tekanan 20 bar dan temperatur maksimal $260^{\circ} \mathrm{C}$ diarahkan untuk memutar turbin sehingga menghasilkan daya mekanik berupa putaran.

4. Keempat, generator yang dikopel langsung dengan turbin berputar menghasilkan energi listrik sebagai hasil dari perputaran medan magnet dalam kumparan, sehingga ketika turbin berputar dihasilkan energi listrik dari terminal output generator.

5. Kelima, uap bekas keluar turbin masuk ke kondensor untuk didinginkan dengan air pendingin agar berubah kembali menjadi air yang disebut air kondensat. Air kondensat hasil kondensasi uap kemudian digunakan lagi sebagai air pengisi boiler.

6. Demikian siklus ini berlangsung terus menerus dan berulang-ulang.

\section{d. Perhitungan Potensi Listrik yang dihasilkan Serabut} dan Cangkang

Jumlah bahan bakar yang tersedia pada PKS dengan kapasitas 36,204 ton TBS/jam, maka dihasilkan TBS/shift masing-masing :

1. Serabut $=13 \% \times 36,204$ ton $=4,706$ ton $\times 7$ jam $=32,945$ ton/ shift

2. Cangkang $=6 \% \times 36,204$ ton $=2,172$ ton $\times 7$ jam $=15,205$ ton/ shift

a) Kapasitas Turbin

$$
\begin{array}{ll}
\mathrm{E}_{\mathrm{g}} & =1.179 \mathrm{~kW} \\
(\mathrm{t}) \mathrm{E} & =7 \mathrm{jam} / \text { shift } \\
\mathrm{TE} & =\sum_{g=1}^{n} \quad \mathrm{Eg} \times \sum(\mathrm{t}) \mathrm{E} \\
\mathrm{TE} & =1.179 \mathrm{~kW} \times 7 \mathrm{jam} \\
& =8.253 \mathrm{kWh}
\end{array}
$$

b) Kebutuhan Listrik Pabrik

$$
\begin{array}{lll}
\mathrm{E}_{\mathrm{g}} & =700 \mathrm{~kW} \\
(\mathrm{t}) \mathrm{E} & =7 \mathrm{jam} / \text { shift } \\
\mathrm{TE} & =\sum_{g=1}^{n} \quad \mathrm{Eg} \times \sum(\mathrm{t}) \mathrm{E} \\
\mathrm{TE} & =700 \mathrm{~kW} \times 7 \mathrm{jam} \\
& =4.900 \mathrm{kWh}
\end{array}
$$


G.M.Saragih, Hadrah, Rahmad Fatulloh, Analisis Pemanfaatan Limbah Padat Pabrik Kelapa Sawit menjadi Bahan Bakar PLTU (Studi Kasus : PT. Agro Mitra Madani Kabupaten Tanjung Jabung Barat)

Perhitungan total energi yang dihasilkan dari pemanfaatan serabut dan cangkang diperoleh dari bahan bakar cangkang tersedia yaitu 15,205 ton/shift dan bahan bakar serabut tersedia yaitu 32,945 ton/shift. Hasil perkalian antara kebutuhan listrik pabrik dengan lama penggunaan bahan bakar sebesar $4.900 \mathrm{kWh}$. Sedangkan total energi yang di hasilkan dari turbin yaitu $8.253 \mathrm{kWh}$. Maka dapat dilihat kelebihan daya selama 7 jam yaitu sebesar $3.353 \mathrm{kWh}$.

Pada 1 jam di awal pengoperasian pabrik memanfaatkan solar sebagai umpan untuk menghidupkan boiler. Jumlah pemakaian solar pabrik sebagai umpan boiler adalah 39.5 liter/jam.

\section{e. Konsumsi Energi Listrik PKS PT Agro Mitra Madani}

Diketahui rata-rata penggunaan listrik pabrik per hari dan rata-rata $\cos \varnothing$ adalah 0.8 yang berarti penggunaan energi sudah efisiensi karena mendekati angka 1. Total energi yang dibutuhkan oleh pabrik kelapa sawit AMM per shift adalah $4.900 \mathrm{kWh}$ diperoleh dari hasil perkalian antara jumlah kebutuhan listrik dengan lama pabrik beroperasi/shift. Penggunaan daya listrik untuk proses pengolahan lebih dominan sebesar $77 \%$. Beban perumahan menempati urutan kedua mencapai $16 \%$ antara lain perumahan AMM, melur, barak, dan perumahan karyawan. Sedangkan beban lain berupa, kantor HO, kantor AMM, sekolah, masjid dan penerangan jalan memiliki nilai yang kecil berkisar $7 \%$.

\section{f. Variasi Jumlah Residu Berdasarkan Lama Pembakaran}

Tabel 1. Jumlah Residu Berdasarkan Lama Pembakaran pada sampel 1

\begin{tabular}{|c|c|c|c|c|c|c|}
\hline \multicolumn{7}{|c|}{ HARI/TGL : JUMAT/27-12-19 } \\
\hline \multirow{3}{*}{ TBS/JAM } & \multirow{3}{*}{ JAM } & \multicolumn{2}{|c|}{ JUMLAH LIMBAH (KG) } & \multirow{3}{*}{$\mathrm{AM}$} & \multirow{3}{*}{ KW } & \multirow{3}{*}{$\begin{array}{c}\text { VOLUME } \\
\text { RESIDU } \\
(\mathrm{KG})\end{array}$} \\
\hline & & CANGKANG & SERABUT & & & \\
\hline & & $25 \%$ & $75 \%$ & & & \\
\hline \multirow{8}{*}{33.412} & $9: 15$ & & & & & \multirow{8}{*}{$630 \mathrm{KG}$} \\
\hline & $10: 00$ & $2.004,72$ & $4.343,56$ & 1000 & 600 & \\
\hline & $11: 00$ & $2.004,72$ & $4.343,56$ & 1200 & 700 & \\
\hline & $12: 00$ & $2.004,72$ & $4.343,56$ & 1100 & 650 & \\
\hline & $13: 00$ & $2.004,72$ & $4.343,56$ & 1100 & 650 & \\
\hline & $14: 00$ & $2.004,72$ & $4.343,56$ & 1100 & 650 & \\
\hline & $15: 00$ & $2.004,72$ & $4.343,56$ & 1200 & 700 & \\
\hline & & & & 1116,67 & 658,333 & \\
\hline
\end{tabular}

Tabel 2. Jumlah Residu Berdasarkan Lama Pembakaran pada sampel 2

\begin{tabular}{|c|c|c|c|c|c|c|}
\hline \multicolumn{7}{|c|}{ HARI/TGL : SENIN/30-12-19 } \\
\hline \multirow{8}{*}{40.362} & $10: 00$ & & & & & \multirow{8}{*}{$650 \mathrm{KG}$} \\
\hline & $11: 00$ & $2.421,72$ & $5.247,06$ & 1100 & 650 & \\
\hline & $12: 00$ & $2.421,72$ & $5.247,06$ & 1000 & 600 & \\
\hline & 13:00 & $2.421,72$ & $5.247,06$ & 1000 & 600 & \\
\hline & $14: 00$ & $2.421,72$ & $5.247,06$ & 1100 & 650 & \\
\hline & 15:00 & $2.421,72$ & $5.247,06$ & 1100 & 650 & \\
\hline & $16: 00$ & $2.421,72$ & $5.247,06$ & 1100 & 650 & \\
\hline & & & & 1066,67 & 633,333 & \\
\hline
\end{tabular}

Tabel 3. Jumlah Residu Berdasarkan Lama Pembakaran pada sampel 3

\begin{tabular}{|r|r|c|c|c|c|c|}
\hline \multicolumn{7}{|c|}{ HARI/TGL : JUM,AT/03-01-20 } \\
\hline \multirow{10}{*}{36.462} & & & & \\
\cline { 2 - 6 } & $9: 00$ & & $2.187,72$ & $4.740,06$ & 1000 & 600 \\
\cline { 2 - 6 } & $11: 00$ & $2.187,72$ & $4.740,06$ & 900 & 550 \\
\cline { 2 - 6 } & $12: 00$ & $2.187,72$ & $4.740,06$ & 900 & 550 \\
\cline { 2 - 6 } & $13: 00$ & $2.187,72$ & $4.740,06$ & 900 & 550 \\
\cline { 2 - 6 } & $14: 00$ & $2.187,72$ & $4.740,06$ & 1100 & 650 \\
\cline { 2 - 6 } & $15: 00$ & $2.187,72$ & $4.740,06$ & 1000 & 600 \\
\hline & & & 966,667 & 583,333 \\
\hline
\end{tabular}

Tabel 4. Jumlah Residu Berdasarkan Lama Pembakaran pada sampel 4

\begin{tabular}{|c|c|c|c|c|c|c|}
\hline \multicolumn{7}{|c|}{ HARI/TGL : SELASA/14-01-20 } \\
\hline \multirow{7}{*}{36.654} & $11: 00$ & & & & & \multirow{7}{*}{$680 \mathrm{KG}$} \\
\hline & $12: 00$ & $2.199,24$ & $4.765,02$ & 1100 & 650 & \\
\hline & $13: 00$ & $2.199,24$ & $4.765,02$ & 1100 & 650 & \\
\hline & $14: 00$ & $2.199,24$ & $4.765,02$ & 1100 & 650 & \\
\hline & $15: 00$ & $2.199,24$ & $4.765,02$ & 1100 & 650 & \\
\hline & $16: 00$ & $2.199,24$ & $4.765,02$ & 1000 & 600 & \\
\hline & & & & 1080 & 640 & \\
\hline
\end{tabular}

Tabel 5. Jumlah Residu Berdasarkan Lama Pembakaran pada sampel 5

\begin{tabular}{|c|c|c|c|c|c|c|}
\hline \multicolumn{7}{|c|}{ HARI/TGL : JUMAT/17-01-20 } \\
\hline \multirow{7}{*}{34.130} & $11: 30$ & & & & & \multirow{7}{*}{$590 \mathrm{KG}$} \\
\hline & 12:00 & $2.047,80$ & $4.436,90$ & 1000 & 600 & \\
\hline & 13:00 & $2.047,80$ & $4.436,90$ & 1100 & 650 & \\
\hline & 14:00 & $2.047,80$ & $4.436,90$ & 1100 & 650 & \\
\hline & 15:00 & $2.047,80$ & $4.436,90$ & 1100 & 650 & \\
\hline & $16: 00$ & $2.047,80$ & $4.436,90$ & 1000 & 600 & \\
\hline & & & & 1060 & 620 & \\
\hline
\end{tabular}

Ket:

$\mathrm{AM}=$ Ampere

$\mathrm{kW} \quad=$ Kilo Watt

$\mathrm{kWh}=$ Kilo Watt Hour

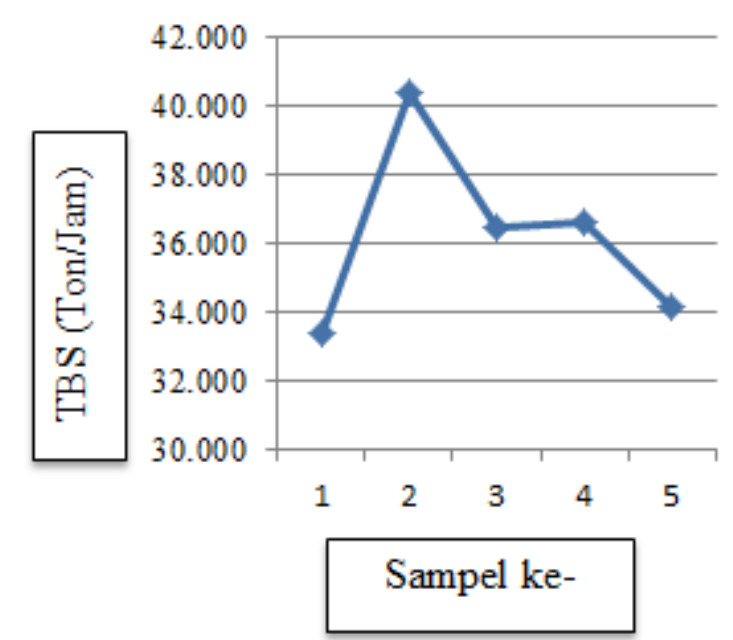

Gambar 3 Jumlah olah TBS/sampel 
G.M.Saragih, Hadrah, Rahmad Fatulloh, Analisis Pemanfaatan Limbah Padat Pabrik Kelapa Sawit menjadi Bahan Bakar PLTU (Studi Kasus : PT. Agro Mitra Madani Kabupaten Tanjung Jabung Barat)

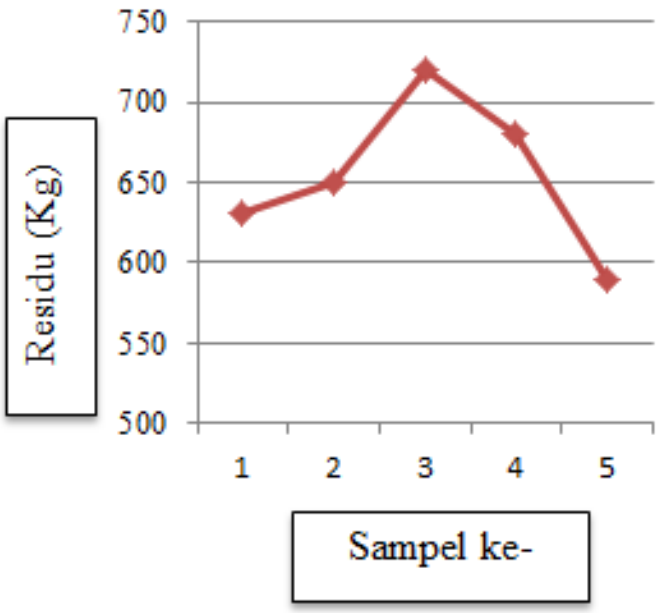

Gambar 4 Jumlah Residu Berdasarkan Lama Pembakaran

Naik turunya jumlah residu pada grafik di atas dipengaruhi dengan adanya kandungan minyak yang masih terikut pada setrabut dan cangkang dari pengolahah TBS. Seiring dengan lamanya pembakaran, maka volume residu akan bertambah dengan perbandingan jumlah residu sebesar $94,733 \mathrm{~kg} / \mathrm{jam}$ dengan jumlah olah TBS rata-rata 36,204 ton/jam.

\section{Kesimpulan}

Cangkang dan serabut kelapa sawit menghasilkan energi yang di dapat dari hasil perkalian antara kebutuhan listrik pabrik dengan lama penggunaan bahan bakar sebesar $4.900 \mathrm{kWh}$. Sedangkan total energi yang di hasilkan dari turbin yaitu $8.253 \mathrm{kWh}$. Maka dapat dilihat kelebihan daya selama 7 jam yaitu sebesar $3.353 \mathrm{kWh}$.

\section{Daftar Pustaka}

Ayustaningwarno, Fitriyono. (2012). Proses Pengolahan dan Aplikasi Minyak Sawit Merah Pada Industri Pangan Program Studi Ilmu Gizi Fakultas Kedokteran Universitas Diponegoro. Semarang : Vitasphere II

Badan Pusat Statiskik. (2017). Statistik Kelapa Sawit Indonesia. Jakarta : CV. Darmaputra

Dinata, T.A., dkk. (2019). Studi Pemanfaatan Biomasaa Limbah Padat Pabrik Kelapa Sawit (PKS) untuk Pembangkit Energi Listrik. Pontianak : Universitas Tanjungpura

Hasibuan, H.C., dkk (2013) Analisa Pemakaian Bahan Bakar dengan Melakukan Pengujian Nilai Kalor Terhadap Perfomansi Ketel Uap Tipe Pipa Air dengan Kapasitas 60ton/jam. Medan : Usu.

Kunarto. (2019). Analisa Efisiensi Boiler Pabrik Kelapa Sawit dengan Menggunakan Bahan Bakar Fibre dan Cangkabng. Lampung : UBL.

Pane, N.E.P., dkk. Studi Potensi Energi Baru Terbarukan Untuk Mengatasi Defisit Pasokan Tenaga Listrik di Daerah Sumatera Utara. Medan : USU. Jumal Singuda Ensikom Vol 14 NO.38/JANUARI 2016 : 1-6.

Parinduri, Luthfi. Analisa Pemanfaatan Biomasa Pabrik Kelapa Sawit untuk Sumber Pembangkit Listrik. Medan : UI Sumatera Utara. Journal of Electrical Technology Vol. I No. 2
Pricilia, S.A. (2014). Analisis Ekonomi Pemanfaatan Fiber dan Cangkang Kelapa Sawit Menjadi Energi Listrik. Bogor : ITB.

Rahman, Aulia. (2018). Karakteristik Bahan Bakar Biomassa Jenis Tandan, Cangkang, dan Serat Kelapa Sawit Serta Pengaruh Timbulnya Pengotoran Alat Penukar Kalor pada Katel Uap. Medan : USU

Susanto, J.P., dkk. (2017). Perhitungan Potensi Limbah Padat Kelapaa Sawit untuk Sumber Energi Terbaharukan dengan Metode LCA.Tanggerang Selatan : Penelitian Pusat Teknologi Lingkungan. 